\title{
Environmental policy and profitability Evidence from Swedish industry
}

\author{
Runar Brännlund ${ }^{* \dagger}$ and Tommy Lundgren ${ }^{* \wedge}$ \\ *Department of Forest Economics \\ Swedish University of Agricultural Sciences \\ Umeå, Sweden \\ ${ }^{\dagger}$ Department of Economics \\ Umeå University \\ Umeå, Sweden \\ ^School of Business \\ Umeå University \\ Umeå, Sweden
}

\begin{abstract}
The purpose of this paper is to investigate the existence of a "Porter effect" using firm level data on output and inputs from Swedish industry between 1990 and 2004. By utilizing a factor demand modeling approach, and specifying a profit function which has a technology component dependent upon firm specific effective tax on $\mathrm{CO} 2$, we are able to separate out the effect of regulatory pressure on technological progress. The results indicate that there is evidence of a reversed "Porter effect" in most industrial sectors, specifically energy intensive industries.
\end{abstract}

Keywords: CO2 tax, factor demands, induced technological change, Porter argument. JEL-codes: D20, H23, Q52, Q55. 


\section{Introduction}

The objective of this study is to evaluate the potential effects on Swedish manufacturing industry in terms of input demand, output and profits of the Swedish $\mathrm{CO}_{2}$ tax regime that started 1991. More specifically the objective is to test the so called Porter hypothesis, i.e. whether environmental regulations (the right kind), that usually is associated with costs, triggers mechanisms that enhances efficiency and productivity that finally outweighs the initial cost increase. To test our hypothesis we develop an econometric partial equilibrium model for the Swedish industrial sector which relies on firm-level data from 1990 to 2004. The model deviates from the standard setting by allowing for a kind of a firm level policy induced technological progress in the sense that the changes in the $\mathrm{CO} 2$ tax is allowed to affect productivity through changes in technological progress. ${ }^{1}$ Thus, given this particular set up the model, apart from providing standard static estimates of supply and demand elasticities, allows us to test for a more potential dynamic effect due to the tax effect on productivity.

The background to our study can be traced back to an idea presented by a one page article in Scientific American 1991 (Porter, 1991) where Michael Porter claimed that a strict environmental regulation of the right type may, contrary to the conventional wisdom, lead to an improvement in competitiveness for those firms that are subject to regulation. The idea was elaborated in a paper in the Journal of Economic Perspectives in 1995 (van der Linde and Porter, 1995). In the same issue Palmer et al. (1995) was arguing against van der Linde and Porter. The main argument made by van der Linde and Porter was that the conventional view upon the costs of regulation was too static and do not consider the dynamic nature of the problem. They argued that regulations have dynamic effects that may fully offset what they call the static cost. The reasoning behind their argument is that regulations forces firms to improve and increase internal as well as external efficiency, this through the whole change of the production cycle. Regulations will visualize and identify inefficiencies and hence provide solutions to them. Palmer et al. (1995) argues strongly

\footnotetext{
${ }^{1}$ The seminal reference on endogenous technological change is Romer (1990). For general discussions and reviews on environmental policy and endogenous technical change from a national level perspective see, e.g., Goulder and Schneider (1999), Jaffe et al (2002), Gillingham et al (2007), or Peretto (2008).
} 
against this. Their main argument is that firms can undertake the improvements voluntarily whenever they want. If firms do not undertake these improvements they do not do so because they do not find it profitable.

The rest of the paper is structured as follows. In the next section we elaborate further on the Porter hypothesis, discussing the arguments in favor and against. We also briefly review the literature. In section 3 we present the model underlying the empirical analysis, whereas section 4 provides a description of the data. The estimation results and the tests of the Porter hypothesis are presented in section 5. Section 6, finally, contains some concluding comments and suggestions for future research.

\section{The Porter hypothesis}

As discussed above van der Linde and Porter (1995) argued that a stricter environmental policy do not necessarily imply losses in competitiveness. They base the hypothesis on four arguments.

(1) Regulations are signaling that there are room for efficiency and technological improvements.

(2) Regulations causes an increase in environmental awareness among firms which in addition to efficiency improvements triggers new ways to handle materials as well as product innovations.

(3) Regulations reduces some of the uncertainties that are related to investments. If firms know that they must take measures in order to comply with certain environmental regulations the number of alternatives will be reduced.

(4) Regulations put pressure not only on the firms that are subject to regulations, but also through the whole chain from suppliers of material and equipment to customers. To support their hypothesis van der Linde and Porter referred to a number of cases where it seems as if tighter environmental regulations have reduced overall costs for the firms, and/or improved the quality of their products. The case studies referred to were mostly firms within the U.S. chemical industry. 
Palmer et al. (1995) argued against the hypothesis, and opposed strongly to the view by van der Linde and Porter that neoclassical economists generally had a too static mindset view on the costs of environmental regulations. Instead, Palmer et al. pointed at two fundamental differences between the Porter view and the neoclassical view. The first, according to Palmer et al., is that van der Linde and Porter presume that private companies systematically overlook profitable opportunities. Second, and perhaps more important, is that within the Porter view lies the presumption that the regulatory authority not only can identify these opportunities, but also can correct for those kind of failures.

The articles by van der Linde and Porter and Palmer et al. have triggered substantial theoretical and empirical research, as well as a lively discussion of the exact meaning of the Porter hypothesis. Within the theoretical literature there has been a search for basic mechanisms that may give rise to the kind of (somewhat unclear) effects that are inherent in the Porter hypothesis. The empirical literature follows a number of different branches of the Porter hypothesis, and at best they can provide partial tests of the hypothesis. The empirical literature suffers from the vagueness of the Porter hypothesis as such, but also of what is meant by "environmental regulations" and how to measure them.

Broadly speaking there are three different interpretations of the Porter hypothesis, all linked to the discussion above.

(1) Absolute cost reductions for the regulated firms. That is, private costs for those firms that are subject to regulations are reduced. This may go through different channels (Gabel and Sinclair-Desgagné, 2001), such as improvements in internal and external organization which remove initial inefficiencies.

(2) Relative (to other firms) improvement in competitiveness. Although a regulation may raise cost for those who are directly regulated, it may be due to learning effects be more costly for those firms that are regulated later. This is what Porter denotes earlymover-advantage (Gabel and Sinclair-Desgagné, 2001).

(3) On a national level, there may be competitiveness improvements due to an increase in demand for products and services complementary to environmental regulations. This 
means that it is not the regulated firms per se that gains, but firms that delivers material and equipment to the regulated firms. Thus, according to Porter, countries that regulates may develop new products and/or equipment that can be sold to other countries when they become regulated, and hence get a relative competitive edge (van der Linde and Porter, 1995).

The theoretical explanations that have emerged can roughly be classified within the three categories, or interpretations, as described above.

(1) Models where firms are inefficient because of bounded rationality and problems with co-ordination within the company (Gabel and Sinclair-Desgagné, 1998, 2001).

(2) Models that focus learning, spillovers and other positive externalities related to investments and research and development (Mohr, 2002).

(3) Models with imperfect markets and strategic interactions (Simpson and Bradford 1996, Greaker 2006, Xepapadeas and de Zeeuw 1999).

Xepapadeas and de Zeeuw (1999) shows that the Porter effect they derive do not completely offset the initial cost of the regulation (a tax), but that the trade off between environmental regulations and competitiveness may not, under specific assumptions, be as sharp as one would expect. The latter is based on very central assumptions; the first is that there are two firms of which one (domestic) is subject to a regulation, and the other (foreign) is not. This assumption simply means that the firms output decision affect the market price (the product is demanded in a third country). The second crucial assumption is that the firm's capital stock consists of different vintages, where new ones are more productive and cleaner than old ones. A regulation will then provide an incentive to invest in a new machine. Investment in a new machine will then mean less pollution but they still have a cost for the investment. The higher cost, however, will due to the first assumption have a "scale effect" in the sense that production goes down with the consequence that the price of the product increases, which to some extent off set the initial cost. Simpson and Bradford (1996) succeed to show, under similar assumptions, that the regulated (domestic) firm increases its profit under the regulation scheme. But as they say; "In our model we 
find that this (domestic industrial advantage) may be a theoretical possibility, but that it is extremely dubious as practical advice." (Simpson and Bradford, 1996, page 296).

Mohr (2002), on the other hand, shows that there is a possibility that the costs from a regulation are more than neutralized under conditions that are similar discussed above. However, he adds another crucial assumption concerning learning. He assumes that there are many firms, but that they learn from each other. This learning effect means that there is a positive externality related to each firm's investment. Regulations will then internalize also this externality. So, one can say that this specific result - that there may exist a Porter effect - is driven by the assumption that there happen to be an additional externality that is removed as a side effect of the regulation. Another conclusion that may be drawn is that environmental regulations are not unique in this sense. Any regulation which causes firms to invest earlier will do the job. Furthermore, as is shown in Feichtinger et.al. (2005), this type of effect may demand a further tightening of the regulation (higher tax), which in the end lead to a loss in profits, hence rejecting the Porter hypothesis.

Another type of externality is analyzed in Greaker (2006). The idea here is that regulations give rise to a complete new industry producing abatement equipment. A regulation will boost demand for abatement equipment. It is assumed that there are high fixed costs for developing abatement equipment, and the boost in demand implies then lower average costs. The lower cost of abatement equipment may then neutralize the cost for the downstream firm (the one that is regulated). Crucial for the result, although not sufficient, is that the price of abatement capital falls as a result of the regulation. The assumptions made may be a reasonable description of reality in the beginning of a regulation process. However, in time when also the competitors become regulated they can also utilize the lower cost capital, which in turn will lower the price on the downstream market and neutralize the domestic competitive advantage. Interestingly there are many similarities between Greaker's model and Porter's cluster theory (Porter, 1990) of the dynamics between downstream and upstream firms.

As with the theoretical literature the empirical literature can be divided into different categories, testing various parts of the Porter hypothesis. The main categories are $(i)$ those 
testing the effects of regulations on investments and innovation, and (ii) those testing the effects on efficiency and productivity. In addition there is a substantial literature on regulatory effect on trade and firm location (see Jaffee et al. 1995 for an overview).

The literature on innovation effects gives no clear answers to what extent regulations affects innovations. Jaffee and Palmer (1997) find no evidence that the number of successful patents would increase in the American industry as a results of tighter environmental regulations, although they find that the expenditure on abatement increases as a result of regulations. Brunneheimer and Cohen (2003), however, find a weak relationship between the number of patents and regulations in the American industry. The latter study differs from Jaffe and Palmer in the sense that Brunneheimer and Cohen focus patents related to environmental innovations. Popp (2002), using a distributed lag model, estimates the elasticity of energy patenting activity with respect to energy prices. He finds that the long-run energy $R \& D$ elasticity is 0.35 , and that a price increase stimulate $R \& D$ quickly (See also Popp 2005 for a review of the innovation effect literature). For the Japanese manufacturing industry, Hamamoto (2006) finds a positive relationship between investment in $R \& D$ and regulations.

Concerning the effects on productivity and/or effeciency there is no clear or strong evidence in favor of the Porter hypothesis. On the contrary, many studies find a negative relation between environmental regulation and firm productivity or efficiency. Gollop and Roberts (1983) found that the sulfur regulations applied on American electrical utilities slowed down productivity growth by $43 \%$ in the 70 -ties. Similar results were found in Smith and Sims (1985), Barbera and McConell (1990), and Gray and Shadbegian (2003). Berman and Bui (2001), however, find that refineries located in south California (where regulations are relatively stringent) have had a significantly higher productivity than refineries in other parts of the US. Alpay et al. (2002) find a similar result for the Mexican food industry. Hamamoto (2006) finds that environmental regulations have had a positive effect on productivity in Japanese manufacturing, via positive effects on R\&D. In a study of small and medium sized firms within the Dutch horticulture industry Van der Vlist et al. finds that those firms that have engaged in voluntary agreements have become more 
efficient than firms that have not engaged in such agreements. ${ }^{2}$ Piot-Lepetit and Le Moing (2007) sets out to measure changes in productivity in the French pig sector following the introduction of the European regulation addressing water pollution by nitrates from agriculture. They conclude that there is a "win-win" effect with regard to the Porter hypothesis between efficiency and regulation in the French pig sector. In a study related to the Porter argument, Cole and Elliot (2007), it is found that costs that arise due to environmental regulation do not have a statistically significant effect on employment.

It should be pointed out that there are tremendous problems to relate the results from these kinds of studies to the Porter hypothesis as described above. First of all, any positive relationship between innovation and regulation cannot be used in favor of the Porter hypothesis. In fact we would certainly expect investments in $R \& D$ to increase as a result of regulations, but that has little to do with the Porter hypothesis. This holds true also for the studies testing for the relation between regulations and productivity/efficiency. A positive relation works in favor of the Porter hypothesis, but is not a sufficient condition for it to hold. Secondly, the Porter hypothesis asserts that the "right kind" of regulations may neutralize costs. Most of the empirical studies referred to above do not distinguish between different kinds of regulations. In most cases environmental regulations are approximated with expenditures on abatement. Van der Vlist etal. use participation in voluntary agreements as the regulatory variable. However, this may lead to the wrong conclusion due to a selection effect. It can not be ruled out that firms that decide to participate and engage in voluntary agreements are those firms that would invest in new technology anyway.

To summarize; there are no clear evidence against or in favor of the Porter hypothesis. The main reason for this is that most studies do not test for the hypothesis as such, but rather for parts of it. Furthermore, mostly due to lack of data, there is no clear distinction between different types of regulations. Since the Porter hypothesis is based on the assumption that the "right kind" of regulation must be prevalent, the referred studies can hardly be used for a strict test.

In this study we take the latter as a starting point. In 1991 Sweden introduced a specific tax

\footnotetext{
${ }^{2}$ Efficiency means hear the distance from the production frontier.
} 
on carbon dioxide (CO2). The tax is levied on the $\mathrm{CO} 2$ content in fuels. Although the $\mathrm{CO} 2$ tax partly replaced a general energy tax, the introduction of it meant a significant increase in the taxation of fossil fuels. Even though the tax rate per kilogram $\mathrm{CO} 2$ is in principle equal to all firms, the effective tax rate will differ between firms due to a specific deduction system which applies to certain parts of the industry or even specific firms. Thus we can see the Swedish CO2 tax on the industry as a suitable case study. The CO2 tax can certainly be viewed as "right kind" of regulation, and in addition it varies between firms and over time, which makes it suitable for statistical tests.

\section{The model}

In this section we derive the model that will be used in the empirical analysis. The basic structure of the model is based on standard microeconomic foundations, assuming that each firm (a) maximizes profits, (b) operates in a competitive environment, and (c) has a technology that transforms inputs to a single good output, but also produces a bad output in an efficient way. Assumption (a) implies, among other things, that given an output decision, each firm will choose a bundle of inputs that minimizes costs. Assumption (b) implies that all input and output prices are exogenous to the firm. Assumption (c) implies that we can describe the technology with a production function. Apart from this standard set-up we add a technological progress component that may shift the profit function. The novelty in this study is that we allow the technological progress component to be a function of the actual payment of carbon dioxide tax for each firm.

To start with we assume that the technology generally can be expressed as:

$q_{t}=f\left(\mathbf{x}_{t} ; A(\tau, t)\right)$,

where $q$ is output, $f$ is the production function, and $\mathbf{x}=\left[x_{L, t}, x_{K, t}, x_{F, t}, x_{E, t}\right]$ is the input vector where sub-indices $L, K, E, F$ denotes labor, capital, electricity, and fuel, respectively. The production function, $f$, is allowed to depend on technological progress, $A$, which in turn is a function of the $\mathrm{CO} 2$ tax, $\tau$, and time, $t$.

The "bad" output, $\mathrm{CO} 2$, is assumed to be produced in a fixed proportion to the input of fuel 
according to ${ }^{3}$ :

$z_{t}=\gamma \cdot x_{F, t}$

Let $\mathbf{p}=\left[p_{K}, p_{L} \cdot p_{F}, p_{E}\right]$ be the price vector corresponding to $\mathbf{x}$. Then we can write the price on fuels as the price before tax plus the tax, i.e.,

$p_{F, t}=\bar{p}_{F, t}+\gamma \cdot \tau_{t}$

Firm profit can now be expressed as:

$$
\begin{aligned}
\pi_{t} & =P_{t} f\left(\mathbf{x}_{t} ; A\left(\tau_{t}, t\right)\right)-p_{L, t} x_{L, t}-p_{K, t} x_{K, t}-p_{E, t} x_{E, t}-p_{F, t} x_{F, t} \\
& =P_{t} f\left(\mathbf{x}_{t} ; A\left(\tau_{t}, t\right)\right)-p_{L, t} x_{L, t}-p_{K, t} x_{K, t}-p_{E, t} x_{E, t}-\bar{p}_{F, t} x_{F, t}-\tau_{t} z_{t}
\end{aligned}
$$

From (4) we see that the tax may have two different effects; an ordinary effect on costs, and an effect on the technological progress. Generally, we can write the profit function as:

$\Pi\left(P_{t}, \mathbf{p}_{t}, A(\tau, t)\right)=\max \left\{P_{t} f(\cdot)-p_{L, t} x_{L, t}-p_{K, t} x_{K, t}-p_{E, t} x_{E, t}-\bar{p}_{F, t} x_{F, t}-\tau_{t} z_{t}\right\}$

Applying Hotelling's lemma on equation (6) gives us then the output supply and input demand functions that are explicit functions of all input prices, the output price, time, and the $\mathrm{CO} 2$ tax, $\tau$.

From equation (4) (or (6)) it follows that the effect on profit of a $\mathrm{CO} 2$ tax change can be written as (we have omitted the time subscript):

$\frac{\partial \pi}{\partial \tau}=P \frac{\partial f}{\partial A} \frac{\partial A}{\partial \tau}-\frac{\partial p_{F}}{\partial \tau} x_{F}=P \frac{\partial f}{\partial A} \frac{\partial A}{\partial \tau}-\gamma x_{F}$,

where the last equality follows from equation (2). Equation (7) tells us that the effect on

\footnotetext{
${ }^{3}$ Thus, any reduction of $\mathrm{CO} 2$ emissions can only be accomplished by a reduction in fuel input, which in turn can be accomplished by reducing output or increase its productivity. Therefore, an increase of the $\mathrm{CO} 2$ tax affects firm profit through a higher input price (fuel). By assuming a fixed proportion between fuel input and $\mathrm{CO} 2$ we do not have to consider the "multi-output" property explicitly.
} 
profit due to an increase in the $\mathrm{CO} 2$ tax has two effects; a direct effect, the second term, and an indirect effect due to technological progress, the first term on the right hand side. Thus, the more carbon intensive fuel is, the larger is the cost for the firm due to the first effect. From (7) it is clear that for a Porter effect to exist the indirect effect must be higher than the direct cost.

For empirical purposes we need to specify a functional form for the profit function, (6), or the production function (1). Here we employ a normalized quadratic profit function ${ }^{4}$ in which we allow technological progress to be neutral and/or non-neutral, i.e.,

$$
\frac{\Pi}{P}=\alpha_{0}+\sum_{i \in X} \alpha_{p i} \frac{p_{i}}{P}+A(\tau, t)+\frac{1}{2} \sum_{i \in X} \sum_{j \in X} \alpha_{i j} \frac{p_{i}}{P} \cdot \frac{p_{j}}{P}+\sum_{i \in X} \alpha_{i A} A(\tau, t) \frac{p_{i}}{P}
$$

The demand and supply functions can then be expressed as:

$$
\begin{aligned}
& x_{i}^{*}=-\left(\alpha_{p i}+\sum_{i \in X} \alpha_{i j} \frac{p_{j}}{P}+\sum_{i \in X} \alpha_{i A} A(\tau, t)\right), \quad i=L, K, F, E \\
& q^{*}=\alpha_{0}+A(\tau, t)-\frac{1}{2} \sum_{i \in X} \sum_{j \in X} \alpha_{i j} \frac{p_{i}}{P} \cdot \frac{p_{j}}{P}
\end{aligned}
$$

Furthermore we specify a general function for technological progress, $A(\tau, t)$, as:

$$
A(\tau, t)=\gamma_{0} \tau_{t}+\beta_{1} t+\beta_{2} t^{2}+\beta_{3} t^{3}+\sum_{t=2}^{T} \gamma_{t} D_{t} \tau_{t}
$$

where $D_{t}, t=2 \ldots, T$, are time specific dummy variables.

In the estimations we also include firm scale dummies in the profit function (four different

\footnotetext{
${ }^{4}$ Here normalized by output price, $P$. See Lau, 1972, 1974, 1976a-b, 1978, for background of the normalized quadratic profit function and derivation of the elasticity formulas. For a few recent empirical applications of this type of profit function specification, see for example Brännlund and Lundgren, 2007, or Hammar et al, 2008a-b. Other specifications were investigated, such as the Translog and the generalized Leontief, but the normalized quadratic specification was superior in terms of producing parameter estimates that generate theoretically plausible properties of the profit function; i.e., input own-price elasticities are negative, input elasticites with respect to output price are positive, output elasticity with respect to input prices are negative, and, output own-price elasticity is positive.
} 
sizes of firms based on number of employees) that interact with prices. This is a system of $4+2=6$ equations that can be estimated by using standard econometric techniques such as full information maximum likelihood (FIML), generalized methods of moments (GMM), or three stage least squares (3SLS) (see Green, 1993). ${ }^{5}$ The system of equations is estimated for the whole manufacturing industry, the energy intensive industry, the non-energy intensive industry, and separately for the sectors that constitutes the energy intensive industry. This implies that in each of the estimations technology parameters are allowed to fully adapt to the level of aggregation chosen, which means, e.g., that all parameters of the profit function can vary between sectors within the energy intensive sector.

The effect on profit of a tax change can then be written as (assuming that only fossil fuel price is affected by the tax):

$$
\begin{aligned}
\frac{\partial \Pi}{\partial \tau} & =\alpha_{p F}+\sum_{i \in X} \alpha_{F i} \frac{p_{i}}{P}+\frac{\partial A}{\partial \tau}+\sum_{i \in X} \alpha_{i A} A(\tau, t)_{i}+\sum_{i \in X} \alpha_{i A} \frac{p_{i}}{P} \frac{\partial A}{\partial \tau} \\
& =-x_{F}+\frac{\partial A}{\partial \tau}+\sum_{i \in X} \alpha_{i A} \frac{p_{i}}{P} \frac{\partial A}{\partial \tau}
\end{aligned}
$$

Given (8) and (9), it is now straightforward to define the demand and output elasticities as:

$\varepsilon_{i j}=-\alpha_{i j}\left(w_{j} / p\right) / x_{i}$

$\varepsilon_{i p}=-\sum_{j=1}^{n} \varepsilon_{i j}$

$\varepsilon_{p i}=-\varepsilon_{i p}\left(w_{i} / p\right) /\left(x_{i} / q\right)$,

$\varepsilon_{p p}=-\sum_{i=1}^{n} \varepsilon_{p i}$,

Equations (12)-(15) define the demand elasticities, the supply elasticity with respect to input prices, and the own price supply elasticity. From theory it follows that the own price supply effect is positive, whereas the effect on supply from an increase in any input price is

\footnotetext{
${ }^{5}$ Below we appended an error term to each equation and estimate the whole system simultaneously. It is reasonable to assume that the errors between equations are correlated (simultaneity) since one shock will affect all equations.
} 
negative. The own price demand effect is negative, whereas the cross price effects cannot be determined a priori.

It should be noted that the model derived here is based on the assumption that all inputs are flexible (or "non-sticky"). Among other things, this implies that the capital stock is allowed to adjust immediately as a result of price changes. Thus, the model may be viewed as a long run model.

\section{Data}

Table 1 provides an overview of the different sectors in the data set available. The data contains information from all firms in the manufacturing industry in Sweden (SNI10-37).

Table 1. Industry branch code classification of Swedish manufacturing (SNI) according to Statistics Sweden. Numbers within parentheses are sectors that belong to energy intensive industry (base industry).

\begin{tabular}{ll}
\hline SNI (branch code) & Description \\
\hline $10+11+14$ & Mining industry, not iron ore (1) \\
$131+132$ & Mining industry, iron ore (2) \\
$15+16$ & Food industry \\
$17+18+19$ & Textile industry \\
$201+202+203+204+205$ & Wood industry (3) \\
$2111+2112+2121+\ldots+2124$ & Pulp and paper industry (4) \\
22 & Printing and other paper related industry \\
$231+232+233+24$ & Chemical industry (5) \\
$251+252$ & Rubber and plastic industry (6) \\
$261+\ldots+268$ & Stone and non-metal mineral industry (7) \\
$27+28$ & Iron and steel industry (8) \\
29 & Machinery industry \\
$30+\ldots+33$ & Electro industry \\
34 & Motor vehicle industry \\
$35+361+\ldots+366$ & Other manufacturing industry \\
37 & Recycling industry \\
\hline
\end{tabular}


The data set is a plant level unbalanced panel covering the years 1990 to 2004. It contains plants with more than five employees and includes data on output (sales), value added, input data on (quantities and values) labor, electricity and fuels, and gross investment (machinery and buildings). Capital stocks are calculated residually from other data available; value added, cost of capital, and salary paid to employees. ${ }^{6}$ Assuming that value added is compensation to labor and capital (salaries plus capital costs), we can extract the capital stock residually. The data also contains detailed information on emissions of $\mathrm{CO} 2$ and total payment of $\mathrm{CO} 2$ tax for each firm. This enables us to construct a variable for "effective" $\mathrm{CO} 2$ tax, which varies considerably across firms and sectors.

Output price indices ${ }^{7}$ are sector specific, and firm specific input prices are calculated from the costs for labor, electricity, and fuels. The calculation of the price of capital is based on national and industry based indices, respectively, which seems plausible considering that firms have limited opportunities to affect the prices for capital (global market) significantly. For capital cost we use the standard definition of user cost of capital, ${ }^{8}$ which is a function of an investment goods index, a sector output price index, an interest rate, and capital depreciation rates. The depreciation rates used are 8.7 per cent for machinery and 2.9 per cent for buildings (the two main components of gross investments). ${ }^{9}$

In sum, firms produce a sector specific output, and use labor, capital, electricity, fuel, and road transports as inputs. Firms are faced with an output price at the sector level, but pay firm specific prices for labor, electricity, and fuels. Price of capital is based on sector and national level price indices. Regulatory pressure is represented by actual payment of $\mathrm{CO}_{2}$ tax per kilo $\mathrm{CO}_{2}$, which differs quite significantly across firms.

Descriptives for the cost shares for energy intensive (EI) and non-energy intensive (NEI) industry are displayed in table 2 , both as an average over the whole period, and for the first and last year in the sample. In figure 1a-b the development of the $\mathrm{CO} 2$ tax over time is

\footnotetext{
${ }^{6}$ Assuming that value added is $V A=p_{L} L+p_{K} K$, i.e., compensation to primary factors of production.

${ }^{7}$ Collected from Statistics Sweden, see producer price index section at the website www.scb.se.

${ }^{8}$ See for example Jorgenson (1963) or Nickell (1978) for a discussion and derivation of user cost of capital.

${ }^{9}$ These rates are based on estimations from Swedish industry data in King and Fullerton (1984) and Bergman (1996).
} 
portrayed in box-plots for the EI and NEI industries.

Table 2. Cost shares for labor, capital, electricity, and fuels. Average for 1990-2004 and for 1990 and 2004.

\begin{tabular}{llcc|cc|cc}
\hline & & \multicolumn{2}{c|}{$1991-2004$} & \multicolumn{2}{c|}{1991} & \multicolumn{2}{c}{2004} \\
\hline \multirow{4}{*}{ Labor, $L$} & EI & 0.69 & 0.19 & 0.72 & 0.19 & 0.72 & 0.18 \\
& NEI & 0.75 & 0.18 & 0.77 & 0.17 & 0.75 & 0.18 \\
Capital, $K$ & EI & 0.24 & 0.18 & 0.21 & 0.18 & 0.21 & 0.17 \\
& NEI & 0.21 & 0.18 & 0.19 & 0.17 & 0.20 & 0.18 \\
Electricity, $E$ & EI & 0.04 & 0.05 & 0.04 & 0.05 & 0.04 & 0.06 \\
& NEI & 0.02 & 0.03 & 0.02 & 0.02 & 0.03 & 0.03 \\
Fuel, $F$ & EI & 0.03 & 0.04 & 0.03 & 0.04 & 0.03 & 0.06 \\
NOBS & NEI & 0.02 & 0.03 & 0.02 & 0.03 & 0.02 & 0.03 \\
& EI & \multicolumn{2}{c}{35089} & 4505 & & 2347 & \\
& NEI & 41923 & 3295 & & 1286 & \\
\hline
\end{tabular}

$\mathrm{EI}=$ Energy intensive, $\mathrm{NEI}=$ non-energy intensive

From table 2 we see that cost shares for the inputs used in production have not changed significantly during the period between 1990 to 2004. It is also obvious that the difference in fuel use for EI and NEI is not as significant as the difference in the use of electricity. Total mean energy share 1990-2004 for EI is 7\% while for NEI it is $4 \%$.

The box-plots in figure 1 displays the variation of the effective $\mathrm{CO} 2$ price, both over time and within the energy intensive (EI) non energy intensive (NEI) industry in Sweden. It can be seen that the price of $\mathrm{CO} 2$, the effective tax, varies over time both for the EI and NEI part of the industry. We also see that the variation is larger in the NEI industry, and that there is an upward trend over time in the effective $\mathrm{CO} 2$ tax in the NEI industry. Further discussion about this is found in the result section below. 


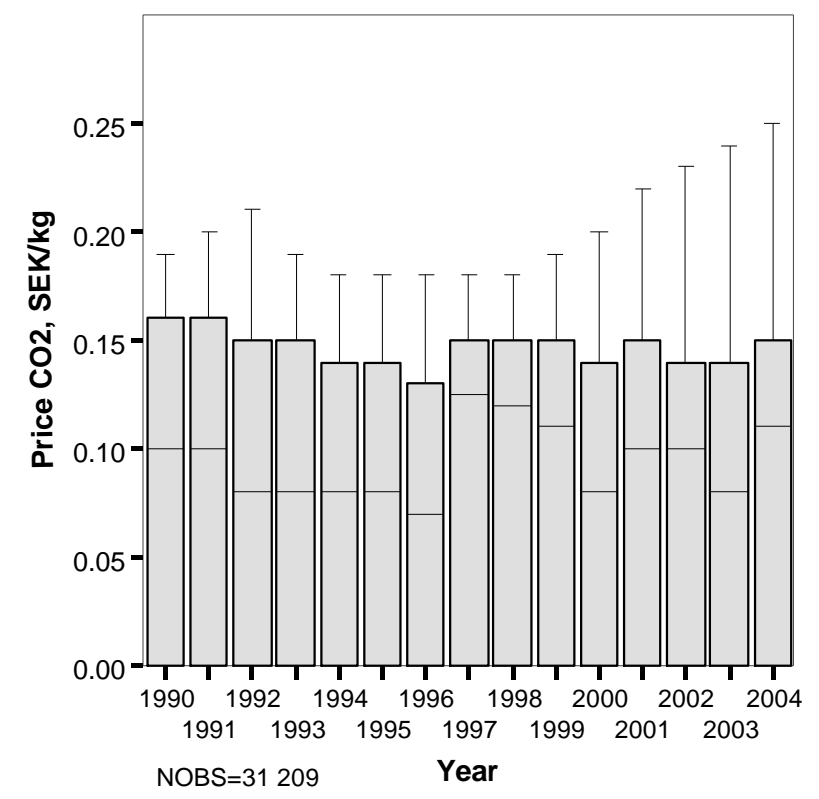

Figure 1a: Effective price on CO2, SEK/kg, 1990 price level. Non energy intensive industry

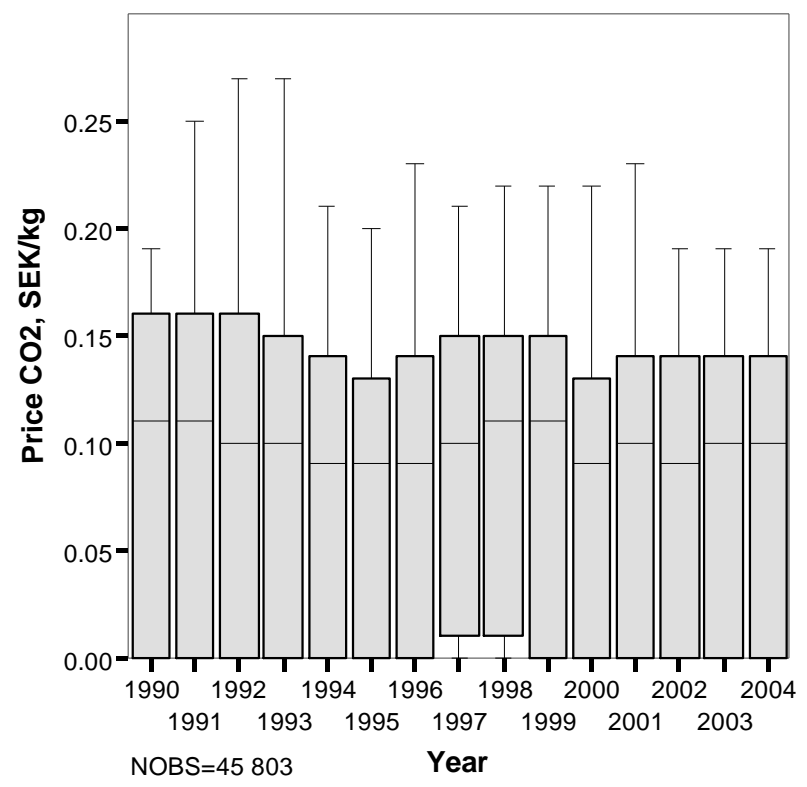

Figure 1b: Effective price on CO2, SEK/kg, 1990 price level. Energy intensive industry

\section{Results}

The main results for the estimations are presented in table $3 a-k$ and 4 . The results in table 3a-k displays the mean price elasticities for the Swedish industry in total, EI and NEI 
separately, and sectors within the EI industry (for sector elasticity matrices, table $3 \mathrm{~d}-\mathrm{k}$, see appendix), evaluated at the year of 2004. Table 4 displays the estimated effect on profits, input demand, and production on each manufacturing sector due to a marginal change in the effective $\mathrm{CO} 2$ price. $^{10}$

Table 3a. Mean price elasticities for the Swedish manufacturing industry, evaluated at the year of 2004. Standard error are computed with the delta method.

\begin{tabular}{lccccc}
\hline & $w$ & $r$ & $p_{e l}$ & $p_{f}$ & $p$ \\
\hline Labor, $L$ & $-0.14^{*}$ & $-0.13^{*}$ & $0.11^{*}$ & $0.13^{*}$ & 0.03 \\
Capital, $K$ & $-0.18^{*}$ & $-0.44^{*}$ & $0.17^{*}$ & 0.03 & $0.43^{*}$ \\
Electricity, $E$ & $0.61^{*}$ & $0.64^{*}$ & $-1.11^{*}$ & $-1.45^{*}$ & $1.32^{*}$ \\
Fuel, $F$ & $0.28^{*}$ & 0.05 & $-0.59^{*}$ & $-0.61^{*}$ & $0.87^{*}$ \\
Output, $q$ & -0.00 & $-0.04^{*}$ & $-0.03^{*}$ & $-0.05^{*}$ & $0.12^{*}$ \\
\hline
\end{tabular}

$w=$ labor cost per hour

$r=$ cost of capital

$p_{e l}=$ price of electricity, SEK per MWh

$p_{b}=$ Price of fuels, SEK per MWh

$p=$ Output price, producer price index

$*$ = Statistically significant different from zero at the $5 \%$ level

Nobs in model estimation $=35089(\mathrm{EI})+41923(\mathrm{NEI})$

The elasticities in table $3 \mathrm{a}$ show theoretically consistent signs and magnitudes that are reasonable, although it can be noted that the own price elasticity for electricity is surprisingly high. An increase in the electricity price will, for the industry as a whole, create a fairly large substitution away from energy to labor and capital, while the output will decrease to a lesser extent (in percentage points). We can also see that an increase in the output price will have substantial effects on electricity and fuel inputs, implying that energy use is quite sensitive to increase in demand for final product.

\footnotetext{
${ }^{10}$ Detailed parameter estimates for the equation systems used to generate the elasticitiy matrices can be retrieved upon request from the authors.
} 
Table 3b. Mean price elasticities for non-energy intensive industry (NEI), evaluated at the year of 2004. Standard error are computed with the delta method.

\begin{tabular}{lccccc}
\hline & $w$ & \multicolumn{2}{l}{$p_{e l}$} & $p_{f}$ & $p$ \\
\hline Labor, $L$ & $-0.56^{*}$ & $-0.11^{*}$ & $-0.01 *$ & 0.00 & $0.68^{*}$ \\
Capital, $K$ & $-0.19^{*}$ & $-0.10^{*}$ & $0.04^{*}$ & $0.09^{*}$ & $0.16^{*}$ \\
Electricity, $E$ & $-0.24 *$ & $0.53 *$ & $-0.53^{*}$ & $-0.80^{*}$ & $1.04^{*}$ \\
Fuel, $F$ & 0.06 & $1.23^{*}$ & $-0.76^{*}$ & $-1.22^{*}$ & $0.71 *$ \\
Output, $q$ & $-0.08^{*}$ & $-0.01^{*}$ & $-0.01 *$ & $-0.00^{*}$ & $0.10^{*}$ \\
\hline
\end{tabular}

$w=$ labor cost per hour

$r=$ cost of capital

$p_{e l}=$ price of electricity, SEK per MWh

$p_{b}=$ Price of fuels, SEK per MWh

$p=$ Output price, producer price index

$*$ = Statistically significant different from zero at the $5 \%$ level

Nobs in model estimation $=41923$

Table 3c. Mean price elasticities for energy intensive industry (EI), evaluated at the year of 2004. Standard error are computed with the delta method.

\begin{tabular}{lccccc}
\hline & $w$ & \multicolumn{2}{l}{$p_{e l}$} & $p_{f}$ & $p$ \\
\hline Labor, $L$ & $-0.54 *$ & 0.04 & $-0.10^{*}$ & $-0.28^{*}$ & $0.90^{*}$ \\
Capital, $K$ & 0.05 & $-0.12 *$ & $0.15^{*}$ & 0.01 & -0.09 \\
Electricity, $E$ & $-0.31 *$ & $0.39 *$ & $-1.03 *$ & $-1.29 *$ & $2.24 *$ \\
Fuel, $F$ & $-0.34 *$ & 0.01 & $-0.52 *$ & $-0.49 *$ & $1.34 *$ \\
Output, $q$ & $-0.11 *$ & 0.01 & $-0.09 *$ & $-0.13 *$ & $0.31 *$ \\
\hline
\end{tabular}

$w=$ labor cost per hour

$r=$ cost of capital

$p_{e l}=$ price of electricity, SEK per MWh

$p_{b}=$ Price of fuels, SEK per MWh

$p=$ Output price, producer price index

* = Statistically significant different from zero at the $5 \%$ level

Nobs in model estimation $=35089$ 
The elasticities in table 3b-c imply theoretically consistent signs and the magnitudes can be considered reasonable, except for the output-capital relationship in the EI industry, which, however, is not statistically significant. The electricity and fuel demand elasticities with respect to the output price in EI industries are relatively high in magnitude (2.24 and 1.34 respectively), implying that energy is responding significantly to an increase in demand for the final product, even more than Swedish manufacturing as a whole and the NEI industry. Furthermore, the EI industry is relatively insensitive to price changes in fuel ( 0.49 for EI compared to 1.22 for NEI), implying that the substitution possibilities are more limited in the EI industry than in the NEI industry.

Note that almost all elasticities in tables 3a-c, both own-price and cross-price, are statistically significant and have the a priori expected signs, implying that our empirical model specification is adequate from a theoretical and statistical point of view. The elasticities are linear functions of the technology parameters of the model, and the elasticity matrix is, in our view, a suitable vehicle for summarizing the results in a compact manner. For information and a brief discussion on elasticity estimates at sector level in the EI industry, consult the appendix. We now proceed to investigate the effects of the $\mathrm{CO} 2$ tax on Swedish industry.

Table 4 displays the effect on profits, inputs, and output due to a (marginal) change in the effective $\mathrm{CO} 2$ tax. The effects are expressed as elasticities (valued at means for the period 1990-2004), i.e. the percentage change due to a percentage change in the CO2 tax. The first column displays the direct tax effect due to a higher input price (the first term in equation (11)), whereas the second column shows the indirect effect through technical change (the two last terms in equation (11)). The remaining columns show the total effect on output and the various inputs from a change in the $\mathrm{CO} 2$ tax (elasticities). Thus, a significant positive sign in the second column would imply that a higher $\mathrm{CO} 2$ tax affect profits positively via technological progress, which is a necessary (but not sufficient) condition for a positive Porter effect. 
Table 4. CO2 tax effects on profits, production, and input demands. Elasticities evaluated at mean values 1990-2004 (t-values within parentheses). The first column, $\pi\left(p_{f}\right)$, show the direct effect on profits from a fuel price change. The second column, $\pi(\operatorname{tax})$, is the indirect tax effect via technological change.

\begin{tabular}{lccccccc}
\hline \multicolumn{1}{c}{ Sector } & $\boldsymbol{\pi}\left(p_{f}\right)$ & $\boldsymbol{\pi}(\operatorname{tax})$ & $\boldsymbol{Q}$ & $\boldsymbol{L}$ & $\boldsymbol{K}$ & $\boldsymbol{E}$ & $\boldsymbol{F}$ \\
\hline Non-energy & -0.08 & 0.03 & -0.01 & 0.01 & -0.01 & -0.02 & -0.04 \\
intensive & $(-4.27)$ & $(1.24)$ & $(-1.15)$ & $(1.46)$ & $(-1.23)$ & $(-1.45)$ & $(-1.49)$ \\
Energy intensive & -0.16 & -0.11 & -0.14 & -0.01 & 0.04 & -0.32 & -0.76 \\
& $(-2.81)$ & $(-3.73)$ & $(-6.77)$ & $(-0.83)$ & $(1.94)$ & $(-8.67)$ & $(-9.54)$ \\
Mining - iron ore & -0.24 & -2.32 & -0.11 & 0.10 & -0.36 & 0.06 & -0.10 \\
& $(-2.03)$ & $(-1.42)$ & $(-1.16)$ & $(0.89)$ & $(-1.42)$ & $(0.49)$ & $(-0.58)$ \\
Mining - not iron & -0.05 & 0.00 & 0.00 & -0.00 & -0.00 & 0.00 & -0.00 \\
& $(-0.67)$ & $(0.01)$ & $(0.01)$ & $(-0.01)$ & $(-0.01)$ & $(0.01)$ & $(-0.01)$ \\
Wood & -0.28 & -0.07 & -0.02 & -0.01 & -0.04 & -0.01 & -0.01 \\
& $(-4.36)$ & $(-2.99)$ & $(-2.84)$ & $(-2.18)$ & $(-2.81)$ & $(-1.58)$ & $(-0.69)$ \\
Pulp and paper & -0.22 & -0.16 & -0.47 & -0.13 & -0.19 & -0.28 & -0.57 \\
& $(-4.79)$ & $(-3.74)$ & $(-5.63)$ & $(-5.15)$ & $(-4.42)$ & $(-5.40)$ & $(-4.96)$ \\
Chemical & -0.10 & -0.12 & -0.00 & 0.05 & 0.03 & -0.09 & -0.16 \\
& $(-1.28)$ & $(-1.35)$ & $(-0.00)$ & $(0.89)$ & $(0.80)$ & $(-1.16)$ & $(-0.52)$ \\
Rubber and plastic & -0.09 & 0.15 & 0.06 & 0.07 & 0.07 & 0.02 & -0.38 \\
& $(-6.56)$ & $(3.09)$ & $(2.35)$ & $(3.87)$ & $(2.53)$ & $(0.55)$ & $(-3.76)$ \\
Stone and mineral & -0.82 & -0.32 & -0.62 & 0.00 & -0.25 & -0.33 & -0.76 \\
& $(-4.85)$ & $(-4.62)$ & $(-6.35)$ & $(0.13)$ & $(-4.26)$ & $(-3.78)$ & $(-6.76)$ \\
Iron and steel & -0.25 & -0.11 & -0.14 & -0.09 & 0.01 & -0.40 & -0.68 \\
& $(-1.36)$ & $(-2.57)$ & $(-4.10)$ & $(-4.80)$ & $(0.26)$ & $(-5.23)$ & $(-6.16)$ \\
\hline
\end{tabular}

The results show that the direct tax effect, via the price, is negative for all sectors, as expected since it corresponds to a direct increase in costs. The tax effect via technical change is significantly negative for most of the sectors. An exception is the rubber and plastic industry in which the effect is significantly positive. Furthermore, for the mining (non-iron) industry it seems as if the tax has no effects on profit via technical change. Looking at broader aggregates, the energy intensive and the non-energy intensive industries, reveal that the tax effect via technical change is positive, although not significant different from zero, for the non energy intensive industry, whereas it is significantly 
negative for the energy-intensive industry. Thus it can be concluded that the necessary condition for a positive porter effect is fulfilled only for the rubber and plastic industry. For all other sectors, and the industry as a whole, we find no evidence that the $\mathrm{CO} 2$ tax has lowered the cost via productivity improvements. One explanation to this may be that different sectors in the industry are subject to different kind of exemptions from the tax. We see from table 4 that the tax elasticity is positive for the non-energy intensive industry (but not significant), but negative for the energy intensive. This may seem counter-intuitive at first glance, but may perhaps be a result of the exemptions that are more extensive for the energy intensive industries. In the box-plots in figure 1 it can be seen that the mean price on $\mathrm{CO} 2$, i.e. the tax, fluctuates more over time for the non-energy intensive industry. More importantly, the right tail of the price distribution has become larger over time for the nonenergy intensive industry, compared to the energy intensive industry. That is, more firms that belong to the non-energy industry have been faced with a higher $\mathrm{CO} 2$ price over time, compared to firms in the energy intensive sector. This may have led to a more significant cost pressure on firms that are not subject to exemptions. In summary, it may be the case that energy intensive industry has been more or less unaffected of increases in the nominal $\mathrm{CO} 2$ tax, whereas non energy intensive industries have not.

It should also be stressed that the results presented do not imply that there is no positive productivity development in the manufacturing industry due to an increase in the $\mathrm{CO} 2$ tax. Rather they imply that the productivity development that occurs is independent or slowed down through the indirect tax effect. Thus a negative tax effect may be interpreted as a crowding out effect; i.e., a higher tax, which may or may not lead to an improvement in energy efficiency, is crowding out other potential productivity improvements.

\section{Discussion}

This paper investigates the existence of a "Porter effect" using firm level data on output and inputs from Swedish industry between 1990 and 2004. By utilizing a factor demand modeling approach, and specifying a profit function which has a technology component dependent upon firm specific effective tax on $\mathrm{CO} 2$, we are able to separate out the effect of regulatory pressure on technological progress. The results show some evidence of a 
reversed "Porter effect" in most industrial sectors, specifically energy intensive industries. One possible explanation to this finding is that a tighter regulation, in terms of a higher $\mathrm{CO} 2$ tax, crowds out productive investments. A second explanation is that the $\mathrm{CO} 2$ tax, due to extensive exemptions, has not contributed to the type of pressure that is foreseen by the Porter hypothesis. To some extent this is supported by a look at the data and the results. A third possible explanation is that the model used here does not capture the true effects. There are several potential reasons for the latter; (i) the $\mathrm{CO} 2$ tax do not fully capture the regulatory effect; (ii) the effect on profit goes through a different channel than what is assumed here; (iii) firm's reactions to tax changes follow a dynamic adjustment path that are not taken into account explicitly here.

In conclusion we can say that given the specific setup we find no support for a Porter effect. However, as pointed out above the setup here is rather restrictive, specifically considering the dynamics. It cannot be ruled out that a change in technology due to a change in the $\mathrm{CO} 2$ tax takes more than one year and follow some adjustment path not captured here. Although there is some evidence that firms patenting activity responds relatively quickly on price signals (Popp, 2002), it may very well be the case that the there is a considerable time span between development of new technologies and the use of new and more efficient technologies.

The discussion above opens up for several options concerning future research. Perhaps the most interesting, and important, research direction is to model the technological progress part as an adjustment process taking dynamics explicitly into account. 


\section{References}

Alpay, E., Buccola, S. and Kerkvliet, J. (2002). Productivity Growth and Environmental Regulation in Mexican and U.S. Food Manufacturing. American Journal of Agricultural Economics, 84(4), 887-901.

Barbera, A.J. and McConnell, V. D. (1990). The Impact of Environmental Regulations on Industry Productivity: Direct and Indirect Effects. Journal of Environmental Economics and Management, 18, 50-65.

Berman, E. and Bui, L.T.M. (2001). Environmental regulation and productivity: evidence from oil refineries. The Review of Economics and Statistics, 83(3): 498-510.

Boyd, G A och J D McClelland (1999). The Impact of Environmental Constraints on Productivity Improvement in Integrated Paper Plants. Journal of Environmental Economics and Management, 38, 121-42.

Brännlund, R. and Lundgren, T. (2007). Swedish industry and Kyoto - An assessment of the effects of the European $\mathrm{CO} 2$ emission trading system. Accepted for publication in Energy Policy.

Brunnermeier, S.B. and Cohen, M.A. (2003). Determinants of environmental innovation in US manufacturing industries. Journal of Environmental Economics and Management, 45, 278-293.

Brunnermeier, S.B. and Levinson, A. (2004). Examining the Evidence on Environmental Regulations and Industry Location. Journal of Environment and Development, 13, 6-41.

Cole M. A., R. J. Elliot (2007). Do Environmental Regulations Cost Jobs? An IndustryLevel Analysis of the UK, The B.E. Journal of Economic Analysis and Policy 7(1), article 28.

Feichtinger, G., Hartl, R.F., Kort, P.M., and Veliov, V.M. (2005). Environmental policy, the porter hypothesis and the composition of capital: Effects of learning and technological 
progress. Journal of Environmental Economics and Management, 50, 434-446.

Gillingham K., R. G. Newell, W. A. Pizer (2007). Modeling Endogenous Technological Change for Climate Policy Analysis, Resources for the Future, DP 07-14. Forthcoming Energy Economics.

Gollop, F.M. and Roberts, M.J. (1983). Environmental Regulations and Productivity Growth: The Case of Fossil-fuelled Electric Power Generation. Journal of Political Economy, 91, 654-674.

Goulder L. H., S. H. Schneider (1999). Induced Technological Change and the Attractiveness of CO2 Abatement Policies, Resource and Energy Economics 21, 211-253.

Gray, W.B. and Shadbegian, R.J. (2003). Plant vintage, technology, and environmental regulation. Journal of Environmental Economics and Management, 46, 384-402.

Greaker, M. (2006). Spillovers in the development of new pollution abatement technology: A new look at the Porter-hypothesis. Journal of Environmental Economics and Management, 52, 1411-420.

Hamamoto, M. (2006). Environmental Regulation and the Productivity of Japanes Manufacturing Industries. Resource and Energy Economics, 28, 299-312.

Hammar, H., T. Lundgren, M. Sjöström (2008a). The significance of transport costs in Swedish forest industry, Journal of Transport Economics and Policy 42(1), 83-104.

Hammar, H., T. Lundgren, M. Sjöström, M. Andersson (2008b). The kilometer tax and Swedish industry - Effects on industry sectors and regions, forthcoming Applied Economics.

Jaffe A. B., R. G. Newell, R. N. Stavins (2002). Environmental Policy and Technological Change, Environmental and Resource Economics 22, 41-69.

Jaffe A.B., K. Palmer (1997). Environmental Regulation and Innovation: A Panel Data Study. The Review of Economics and Statistics, 79, 610-619. 
Jaffe A.B., S.R Peterson, P.R Portney, R.N Stavins. (1995). Environmental Regulation and the Competitiveness of U.S. Manufacturing: What Does the Evidence Tell Us? Journal of Economic Literature, XXXIII, 132-163.

Mohr R. D. (2002). Technical Change, External Economies, and the Porter Hypothesis. Journal of Environmental Economics and Management, 43, 158-168.

Palmer, K., Oates, W.E. and Portney, P.R. (1995). Thightening Environmental Standards: The Benefit-Cost or the No-Cost Paradigm? Journal of Economic Perspectives, 9, 119-132.

Peretto P., (2008). Energy Taxes and Endogenous Technological Change, Journal of EnvironmentalEconomics and Management, forthcoming (accepted July 23, 2008).

Piot-Lepetit I., M. Le Moing (2007), Environmental and Resource Economics 38, 433-446.

Popp, D. (2002). Induced innovation and energy prices, American Economic Review, 92, $160-180$.

Popp, D. (2005). Lessons from patents: Using patents to measure technological change in environmental models. Ecological Economics, 54, 209-226

Porter, M. E. (1990). The Competitive Advantage of Nations. The Free Press, New York.

Porter, M. E. (1991). America's Green Strategy. Scientific American, April, p 168.

Romer P. (1990). Endogenous Technological Change, Journal of Political Economy 98, 71102.

Simpson D. and Bradford, R. L. (1996). Taxing Variable Cost: Environmental Regulation as Industrial Policy. Journal of Environmental Economics and Managemen, 30, 282-300.

Smith J.B. and Sims, W.A. (1985). The Impact of Pollution Charges on Productivity Growth in Canadian Brewing. The Rand Journal of Economics, 16, 410-423. 
Xepapadeas, A. and de Zeeuw, A. (1999). Environmental Policy and Competitiveness: The Porter Hypothesis and the Composition of Capital. Journal of Environmental Economics and Management, 37, 165-182.

Van der Vlist, A.J., Withagen, C. and Folmer, H. (2007) Technical efficiency under alternative environmental regulatory regimes: The case of Dutch horticulture. Ecological Economics 63(1), 165-173. 


\section{Appendix}

This appendix present elasticity estimates, tables $3 \mathrm{~d}-\mathrm{k}$, for the sectors that are included in the energy intensive industry. We briefly comment, focusing on energy, on the estimates below each table.

Table 3d. Mean price elasticities for the iron ore mining sector, evaluated at the year of 2004. Standard error are computed with the delta method.

\begin{tabular}{lccccc}
\hline & $w$ & \multicolumn{2}{l}{$p_{e l}$} & \multicolumn{1}{l}{$p_{f}$} & $p$ \\
\hline Labor, $L$ & 0.13 & 0.58 & -0.07 & -0.39 & -0.25 \\
Capital, $K$ & 0.30 & 0.05 & 0.05 & 0.09 & -0.49 \\
Electricity, $E$ & -0.21 & 0.31 & -0.43 & -0.70 & 1.04 \\
Fuel, $F$ & -1.14 & 0.50 & -0.63 & $-1.00 *$ & 2.28 \\
Output, $q$ & 0.03 & $0.12 *$ & -0.04 & -0.10 & -0.01 \\
\hline
\end{tabular}

$w=$ labor cost per hour

$r=$ cost of capital

$p_{e l}=$ price of electricity, SEK per MWh

$p_{b}=$ Price of fuels, SEK per MWh

$p=$ Output price, producer price index

* = Statistically significant different from zero at the $5 \%$ level

Nobs in model estimation $=179$

Due to very few observations in the actual estimation of the model the statistical performance of the elasticity estimates for the iron ore industry are poor. However, we can see that the own price elasticity for fuel, which determines the size of the effect of a CO2 tax increase, is unit elastic and statistically significant. 
Table 3e. Mean price elasticities for the mining - not iron ore - sector, evaluated at the year of 2004. Standard error are computed with the delta method.

\begin{tabular}{lccccc}
\hline & $w$ & \multicolumn{2}{l}{$p_{e l}$} & $p_{f}$ & $p$ \\
\hline Labor, $L$ & $-0.42 *$ & -0.01 & -0.03 & $0.40^{*}$ & 0.06 \\
Capital, $K$ & -0.02 & $-0.12^{*}$ & $-0.16^{*}$ & $0.15^{*}$ & 0.14 \\
Electricity, $E$ & -0.29 & $-1.15^{*}$ & $-1.21^{*}$ & 1.52 & 1.13 \\
Fuel, $F$ & $2.23 *$ & $0.57 *$ & 0.77 & $-1.37 *$ & $2.19 *$ \\
Output, $q$ & -0.01 & -0.02 & -0.02 & $-0.06^{*}$ & 0.02 \\
\hline
\end{tabular}

$w=$ labor cost per hour

$r=$ cost of capital

$p_{e l}=$ price of electricity, SEK per MWh

$p_{b}=$ Price of fuels, SEK per MWh

$p=$ Output price, producer price index

$*$ = Statistically significant different from zero at the $5 \%$ level

Nobs in model estimation $=1300$

The mining sector (not iron ore) show considerable energy demand sensitivity with elasticity estimates -1.21 and -1.37 for electricity and fuel, respectively, which is significantly more elastic than labor and capital with respect to own price. Electricity and especially fuel is elastic with respect to changes in output price. 
Table 3f. Mean price elasticities for the wood $^{11}$ sector, evaluated at the year of 2004 . Standard error are computed with the delta method.

\begin{tabular}{lllccc}
\hline & $w$ & \multicolumn{2}{l}{$p_{e l}$} & $p_{f}$ & $p$ \\
\hline Labor, $L$ & $-0.06^{*}$ & $-0.24 *$ & $0.03^{*}$ & 0.00 & $0.26^{*}$ \\
Capital, $K$ & $-0.52 *$ & $-0.86^{*}$ & $-0.13^{*}$ & $-0.12^{*}$ & $1.62^{*}$ \\
Electricity, $E$ & $0.23 *$ & $-0.38^{*}$ & $-0.39^{*}$ & $-0.15^{*}$ & $0.69^{*}$ \\
Fuel, $F$ & $0.01 *$ & $-0.18^{*}$ & $-0.07 *$ & $-0.21^{*}$ & $0.45^{*}$ \\
Output, $q$ & $-0.02 *$ & -0.07 & $-0.01 *$ & $-0.01 *$ & $0.12 *$ \\
\hline
\end{tabular}

$w=$ labor cost per hour

$r=$ cost of capital

$p_{e l}=$ price of electricity, SEK per MWh

$p_{b}=$ Price of fuels, SEK per MWh

$p=$ Output price, producer price index

$*$ = Statistically significant different from zero at the $5 \%$ level

Nobs in model estimation $=3764$

Almost all elasticities (except two) are statistically significant. Inelastic energy demands imply limited substitution possibilities in case of increase in fuel price due to, e.g., a CO2 tax.

\footnotetext{
${ }^{11}$ Forestry is not included here, it is only firms involved in processing wood, such as sawmills.
} 
Table 3g. Mean price elasticities for the pulp and paper sector, evaluated at the year of 2004. Standard error are computed with the delta method.

\begin{tabular}{lccccc}
\hline & $w$ & \multicolumn{2}{l}{$p_{e l}$} & $p_{f}$ & $p$ \\
\hline Labor, $L$ & $-0.30^{*}$ & $0.26^{*}$ & $-0.50^{*}$ & -0.07 & $0.61^{*}$ \\
Capital, $K$ & $0.21^{*}$ & $-0.46^{*}$ & -0.07 & $-0.28^{*}$ & $0.60^{*}$ \\
Electricity, $E$ & $-0.79^{*}$ & -0.14 & $-0.41^{*}$ & $-0.26^{*}$ & $1.61^{*}$ \\
Fuel, $F$ & -0.05 & $-0.22^{*}$ & $-0.11^{*}$ & $-0.16^{*}$ & $0.53^{*}$ \\
Output, $q$ & $-0.06^{*}$ & $-0.08^{*}$ & $-0.11^{*}$ & $-0.09 *$ & $0.34^{*}$ \\
\hline
\end{tabular}

$w=$ labor cost per hour

$r=$ cost of capital

$p_{e l}=$ price of electricity, SEK per MWh

$p_{b}=$ Price of fuels, SEK per MWh

$p=$ Output price, producer price index

$*$ = Statistically significant different from zero at the $5 \%$ level

Nobs in model estimation $=2445$

Same pattern as in the wood sector; significant estimates with theoretically correct signs, and inelastic energy demands with respect to changes in price of electricity and fuels. Notably, electricity use is quite sensitive to output price change. 
Table 3h. Mean price elasticities for the chemical sector, evaluated at the year of 2004.

Standard error are computed with the delta method.

\begin{tabular}{lccccc}
\hline & $w$ & $r$ & $p_{e l}$ & $p_{f}$ & $p$ \\
\hline Labor, $L$ & -0.10 & 0.24 & 0.01 & -0.16 & 0.01 \\
Capital, $K$ & 0.16 & -0.01 & $0.09^{*}$ & 0.00 & $-0.25^{*}$ \\
Electricity, $E$ & 0.06 & $0.59 *$ & $-1.03^{*}$ & $-0.61^{*}$ & 0.98 \\
Fuel, $F$ & -0.37 & 0.01 & -0.32 & $-0.68^{*}$ & $1.36^{*}$ \\
Output, $q$ & -0.00 & $0.04^{*}$ & -0.02 & $-0.06^{*}$ & 0.05 \\
\hline
\end{tabular}

$w=$ labor cost per hour

$r=$ cost of capital

$p_{e l}=$ price of electricity, SEK per MWh

$p_{b}=$ Price of fuels, SEK per MWh

$p=$ Output price, producer price index

$*$ = Statistically significant different from zero at the $5 \%$ level

Nobs in model estimation $=2769$

The chemical sector show elasticity estimates generally in line with microeconomic predictions (except the output-capital estimates). Fuel is inelastic with respect to own price but seems sensitive (elastic) to output price change. 
Table 3i. Mean price elasticities for the rubber and plastic sector, evaluated at the year of 2004. Standard error are computed with the delta method.

\begin{tabular}{lccccc}
\hline & $w$ & \multicolumn{2}{l}{$p_{e l}$} & $p_{f}$ & $p$ \\
\hline Labor, $L$ & $-0.32 *$ & $-0.09 *$ & 0.02 & $0.07 *$ & $0.33 *$ \\
Capital, $K$ & $-0.21 *$ & $-0.32 *$ & -0.02 & 0.06 & $0.49 *$ \\
Electricity, $E$ & 0.22 & -0.08 & $-0.41 *$ & -0.05 & 0.31 \\
Fuel, $F$ & $1.19 *$ & 0.45 & -0.07 & $-1.43 *$ & -0.14 \\
Output, $q$ & $-0.06 *$ & $-0.04 *$ & -0.00 & 0.00 & 0.10 \\
\hline
\end{tabular}

$w=$ labor cost per hour

$r=$ cost of capital

$p_{e l}=$ price of electricity, SEK per MWh

$p_{b}=$ Price of fuels, SEK per MWh

$p=$ Output price, producer price index

$*$ = Statistically significant different from zero at the $5 \%$ level

Nobs in model estimation $=3245$

The estimated fuel demand is elastic in the rubber and plastic sector and signs and magnitudes of the elasticities are consistent with theory to a large extent. 
Table 3j. Mean price elasticities for the stone and mineral sector, evaluated at the year of 2004. Standard error are computed with the delta method.

\begin{tabular}{llllll}
\hline & $w$ & $r$ & $p_{e l}$ & $p_{f}$ & $p$ \\
\hline Labor, $L$ & -0.11 & $-0.07 *$ & -0.05 & -0.12 & $0.36^{*}$ \\
Capital, $K$ & $-0.22 *$ & $-0.46^{*}$ & -0.07 & $-0.87 *$ & $1.62 *$ \\
Electricity, $E$ & -0.39 & -0.17 & -0.23 & $-0.93^{*}$ & $1.72 *$ \\
Fuel, $F$ & -0.21 & $-0.47 *$ & $-0.19 *$ & $-0.87 *$ & $1.74 *$ \\
Output, $q$ & $-0.07 *$ & $-0.17^{*}$ & $-0.04 *$ & $-0.21 *$ & $0.42 *$ \\
\hline
\end{tabular}

$w=$ labor cost per hour

$r=$ cost of capital

$p_{e l}=$ price of electricity, SEK per MWh

$p_{b}=$ Price of fuels, SEK per MWh

$p=$ Output price, producer price index

$*$ = Statistically significant different from zero at the $5 \%$ level

Nobs in model estimation $=3790$

The stone and mineral sector's energy demand is sensitive to output demand swings, leading to price fluctuations for the final product, according to the associated output price elasticities (1.72 and 1.74). However, fuel and especially electricity are quite insensitive to own price changes (-0.87 and -0.23$)$. 
Table 3k. Mean price elasticities for the iron and steel sector, evaluated at the year of 2004.

Standard error are computed with the delta method.

\begin{tabular}{llllll}
\hline & $w$ & \multicolumn{2}{l}{$p_{e l}$} & $p_{f}$ & $p$ \\
\hline Labor, $L$ & $-0.53 *$ & $-0.34 *$ & -0.04 & $-0.44 *$ & $1.35^{*}$ \\
Capital, $K$ & $-0.57 *$ & $-0.21^{*}$ & -0.11 & $-0.28^{*}$ & $1.17 *$ \\
Electricity, $E$ & -0.20 & -0.32 & $-1.24 *$ & $-2.22 *$ & $3.97^{*}$ \\
Fuel, $F$ & $-1.00 *$ & $-0.38^{*}$ & $-1.03 *$ & $-0.97 *$ & $3.39 *$ \\
Output, $q$ & $-0.17 *$ & $-0.09 *$ & $-0.10 *$ & $-0.19^{*}$ & $0.54 *$ \\
\hline
\end{tabular}

$w=$ labor cost per hour

$r=$ cost of capital

$p_{e l}=$ price of electricity, SEK per MWh

$p_{b}=$ Price of fuels, SEK per MWh

$p=$ Output price, producer price index

$*$ = Statistically significant different from zero at the $5 \%$ level

Nobs in model estimation $=14264$

Demand for energy is very sensitive to changes in output price for iron and steel (elasticities are 3.99 and 3.39 for electricity and fuel, respectively), implying great shifts in energy use caused by shifts in the demand for the final product. Elasticities show, in general, compliance with theory. Own price elasticity for fuel is unit elastic, while electricity is slightly elastic. 